\title{
Produtividade de grãos e componentes de produção da canola de acordo com fontes e doses de nitrogênio
}

\author{
João Edson Kaefer(1), Vandeir Francisco Guimarães(2), Alfredo Richart(1), \\ Gilberto Omar Tomm ${ }^{(3)}$ e Alexandre Luís Müller ${ }^{(1)}$
}

\begin{abstract}
(1)Pontifícia Universidade Católica do Paraná, Campus Toledo, Avenida da União, № 500, CEP 859000-001 Toledo, PR, Brasil. E-mail: edson.kaefer@pucpr.br, alfredo.richart@pucpr.br, alexandre.luis@pucpr.br (2)Universidade Estadual do Oeste do Paraná, Rua Pernambuco, no 177, Caixa Postal 91, CEP 85960-000 Marechal Cândido Rondon, PR, Brasil. E-mail: vandeirfg@yahoo.com.br ${ }^{(3)}$ Embrapa Trigo, BR 285, Km 174, Caixa Postal 451, CEP 99001-970 Passo Fundo, RS, Brasil. E-mail: gilberto.tomm@embrapa.br
\end{abstract}

Resumo - O objetivo deste trabalho foi avaliar a resposta da canola a fontes e doses de nitrogênio aplicadas na semeadura. O experimento foi conduzido em Latossolo Vermelho distroférrico típico, com textura muito argilosa. Utilizou-se delineamento experimental de blocos ao acaso, em arranjo fatorial $7 \mathrm{x} 2$, com sete doses de $\mathrm{N}$ em superfície na semeadura $\left(0,20,40,60,80,100\right.$ e $\left.120 \mathrm{~kg} \mathrm{ha}^{-1}\right)$, duas fontes de $\mathrm{N}$ (sulfato de amônio e ureia) e quatro repetições. O experimento foi realizado com o híbrido Hyola 61, por dois anos, e foram avaliadas as seguintes variáveis: altura de planta, número de plantas por metro quadrado, massa de matéria seca da parte aérea, massa de síliquas por planta, massa de mil grãos, produtividade de grãos, e teores de proteína e de óleo nos grãos. As variáveis não foram influenciadas pelas fontes de N. A maior produtividade de grãos é alcançada com $88 \mathrm{~kg} \mathrm{ha}^{-1}$ de N. Doses crescentes de $\mathrm{N}$ aumentam os teores de proteína e diminuem os de óleo nos grãos de canola.

Termos para indexação: Brassica napus, adubação nitrogenada, sulfato de amônio, teor de óleo, teor de proteína, ureia.

\section{Grain yield and yield components in canola according to nitrogen sources and rates}

\begin{abstract}
The objective of this work was to evaluate the response of canola to nitrogen sources and rates applied at sowing. The experiment was carried out on a dystroferric Red Ferralsol, with a very clayey texture. A randomized complete block design was used, in a $7 \times 2$ factorial arrangement, with seven $\mathrm{N}$ rates applied on soil surface at sowing $\left(0,20,40,60,80,100\right.$, and $\left.120 \mathrm{~kg} \mathrm{ha}^{-1}\right)$, two $\mathrm{N}$ sources (ammonium sulfate and urea), and four replicates. The experiment was carried out with the Hyola 61 hybrid for two years, and the following variables were evaluated: plant height, number of plants per square meter, shoot dry matter mass, pod mass per plant, weight of a thousand grains, grain yield, and protein and oil contents in seeds. The variables were not affected by the $\mathrm{N}$ sources. The highest grain yield is obtained with $88 \mathrm{~kg} \mathrm{ha}^{-1} \mathrm{~N}$. Increasing $\mathrm{N}$ rates increase protein contents and reduce oil contents in canola seeds.
\end{abstract}

Index terms: Brassica napus, nitrogen fertilization, ammonium sulfate, oil content, protein content, urea.

\section{Introdução}

A canola (Brassica napus L. var. oleífera) é uma oleaginosa de inverno desenvolvida a partir do melhoramento genético da colza. Em razão dos preços vantajosos e de sua adaptabilidade às condições edafoclimáticas do Sul do Brasil, a canola vem se tornando, na região, juntamente com o milho safrinha (Zea mays L.) e o trigo (Triticum aestivum L.), uma excelente opção de cultivo de inverno, além de constituir uma sucessão adequada ao cultivo de soja (Glycine max L.).
A canola é uma cultura altamente responsiva à aplicação de N (Rathke et al., 2006; Karaaslan, 2008; Tomm et al., 2009; Narits, 2010; Öztürk, 2010), e o fornecimento desse nutriente para a cultura pode ser feito no momento da semeadura e também em cobertura. No Paquistão, Cheema et al. (2010) relataram produtividade de $2.812 \mathrm{~kg} \mathrm{ha}^{-1}$ de grãos com a aplicação de $20 \mathrm{~kg} \mathrm{ha}^{-1}$ de N. No Canadá, Karamanos et al. (2006) obtiveram produtividade de $2.600 \mathrm{~kg} \mathrm{ha}^{-1}$ de grãos com a aplicação de $160 \mathrm{~kg} \mathrm{ha}^{-1} \mathrm{de} \mathrm{N}$. Portanto, a resposta da cultura à adubação nitrogenada tem sido 
bastante variável, de acordo com as condições de cultivo.

No Brasil, pesquisas sobre a aplicação de $\mathrm{N}$ na semeadura da canola são escassas, especialmente na região oeste do Paraná. As recomendações de cultivo da canola na região norte do Rio Grande do Sul indicam a utilização de $60 \mathrm{~kg} \mathrm{ha}^{-1}$ de $\mathrm{N}$ na semeadura (solos com teor de matéria orgânica inferior a $25 \mathrm{~g} \mathrm{~kg}^{-1}$ ) e mais $20 \mathrm{~kg} \mathrm{ha}^{-1}$ para cada tonelada de grãos esperada acima da produtividade de $1.500 \mathrm{~kg} \mathrm{ha}^{-1}$ (Tomm, 2009). No entanto, essas recomendações não mencionam as fontes de $\mathrm{N}$ mais adequadas para a canola e nem o efeito de doses crescentes de $\mathrm{N}$ na semeadura, sobre a produtividade de grãos.

Além da produtividade de grãos, o $\mathrm{N}$ influencia a produção de matéria seca da parte aérea, a área foliar, o número e a massa seca de síliquas por planta e os teores de óleo nos grãos da canola (Gunasekera et al., 2006; Rathke et al., 2006; Tomm, 2009; Cheema et al., 2010). Contudo, há relatos de ausência de resposta ou até mesmo de efeito negativo de doses excessivas de $\mathrm{N}$ na produtividade de grãos de canola (El-Nakhlawy \& Bakhashwain, 2009; Cheema et al., 2010).

O objetivo deste trabalho foi avaliar a resposta da canola a fontes e doses de nitrogênio aplicadas na semeadura.

\section{Material e Métodos}

Os experimentos foram realizados em Toledo, PR ( $24^{\circ} 43^{\prime} 43^{\prime \prime} \mathrm{S}, 53^{\circ} 46,5^{\prime} 5^{\prime \prime} \mathrm{W}$, a $560 \mathrm{~m}$ de altitude média), em condições de campo, em 2009 e 2010. Os dados meteorológicos (temperatura e precipitação pluvial) foram fornecidos pelo Sistema Meteorológico do Paraná (Simepar) (Figura 1). A precipitação pluvial acumulada foi de $2.258 \mathrm{~mm}$ em 2009 e de $1.744 \mathrm{~mm}$ em 2010.

O solo da unidade experimental foi classificado como Latossolo Vermelho distroférrico típico, de textura muito argilosa (Santos et al., 2006). Amostras de solo foram coletadas à profundidade de $0,0-0,20 \mathrm{~m}$, para análise química conforme metodologia proposta por Miyazawa et al. (1992) (Tabela 1).

Adotou-se o delineamento experimental de blocos ao acaso, em arranjo fatorial $7 \times 2$, com quatro repetições, que consistiram de sete doses de $\mathrm{N}$ aplicadas em superfície na semeadura $(0,20,40,60,80,100$ e $120 \mathrm{~kg} \mathrm{ha}^{-1}$ ) e duas fontes de $\mathrm{N}$ (sulfato de amônio e ureia). Os experimentos foram instalados na mesma área experimental, porém em locais diferentes, nos dois anos agrícolas, nas datas de semeadura de 12/5/2009 e 23/4/2010. Cada parcela foi constituída por 15 linhas de $6 \mathrm{~m}$ de comprimento, com espaçamento de $0,17 \mathrm{~m}$ entre as linhas, num total de $15,3 \mathrm{~m}^{2}(2,55 \times 6 \mathrm{~m})$ por parcela.

As doses de $\mathrm{N}$ foram aplicadas manualmente, por ocasião da semeadura. Utilizou-se semeadora/ adubadora para aplicação de $300 \mathrm{~kg} \mathrm{ha}^{-1}$ de 00-25-25 $\mathrm{N}-\mathrm{P}_{2} \mathrm{O}_{5}-\mathrm{K}_{2} \mathrm{O}$. A adubação de base foi definida conforme Tomm (2007), tendo-se buscado atingir a produtividade de $2.500 \mathrm{~kg} \mathrm{ha}^{-1}$ de grãos. A semeadura foi realizada mecanicamente, com uso de oito a dez sementes por metro, tendo-se buscado estandes de 40 a 50 plantas por metro quadrado.

Utilizou-se o híbrido Hyola 61 que, entre as características relatadas por Tomm (2009), apresenta resistência poligênica ao fungo causador da canela-preta, ciclo médio de 123 a 155 dias, altura média de plantas de 78 a $129 \mathrm{~cm}$ e excelente desempenho sob deficiência hídrica e frio intenso.

Foram avaliadas as características biométricas e os componentes de produção da canola. A coleta das informações foi realizada dentro da área útil de cada parcela, composta de sua área total descontada de um metro em cada extremidade longitudinal e de suas linhas externas em cada lado das parcelas, o que resultou em área de $5 \mathrm{~m}^{2}$.

Quanto às variáveis biométricas: a altura de planta foi obtida da altura do dossel em cinco pontos, tendo-se medido da base até a extremidade superior dos ramos

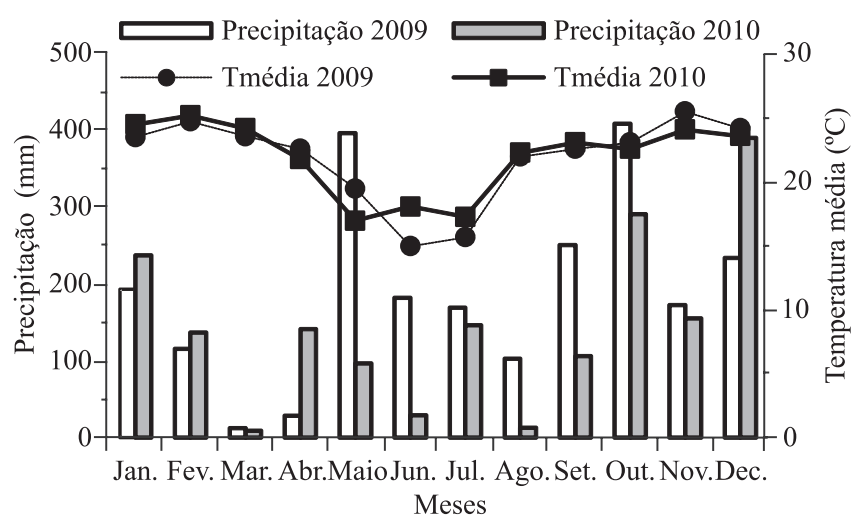

Figura 1. Médias mensais de precipitação pluvial e de temperatura do ar na área experimental, em 2009 e 2010. Fonte: Simepar (2014). 
com síliquas; o número de plantas por metro quadrado foi obtido após a colheita da canola, pela contagem de todas as plantas na área útil; a massa de matéria seca da parte aérea foi determinada no pré-florescimento, com a coleta de cinco plantas por parcela, que foram acondicionadas em sacos de papel e postas para secar em estufa de circulação forçada de ar a $65^{\circ} \mathrm{C}$ até massa constante; e a área foliar foi determinada de acordo com a metodologia proposta por Benincasa (1988).

Quanto aos componentes de produção, a massa de síliquas por planta foi obtida a partir da coleta, em cinco plantas por parcela, e da secagem em estufa de circulação forçada de ar a $65^{\circ} \mathrm{C}$, até massa constante; a massa de mil grãos foi determinada a partir de dez subamostras, com 100 grãos cada uma; e a produtividade de grãos foi obtida da debulha de todas as plantas da parcela útil, em trilhadora mecânica, com posterior secagem dos grãos em estufa a $65^{\circ} \mathrm{C}$, até massa constante. Os componentes da produção e a produtividade tiveram suas massas corrigidas para $10 \%$ de umidade, base úmida, segundo metodologia descrita nas Regras para Análises de Sementes (2009). O teor de proteína bruta dos grãos foi determinado pelo método da digestão sulfúrica, para a quantificação do teor de $\mathrm{N}$ em micro destilador Kjeldahl, conforme
Tedesco et al. (1995), tendo-se multiplicado o valor obtido por 6,25 , para a conversão de $\mathrm{N}$ em proteína bruta (Jones, 1931). Para a determinação do teor de óleo dos grãos, utilizou-se o método do extrato etéreo, adotado por Silva (1990).

Os dados dos experimentos de 2009 e 2010 foram submetidos à análise de variância conjunta e, quando significativos a $5 \%$ de probabilidade pelo teste $\mathrm{F}$, as médias dos diferentes anos foram comparadas pelo teste de $t$ de Student, também a 5\% de probabilidade. Os dados relativos às doses foram submetidos à análise de regressão polinomial, tendo-se utilizado o programa Sisvar (Ferreira, 2009). Utilizou-se o teste t de Student para a escolha da equação de regressão. A dose de $\mathrm{N}$ que resultou na máxima eficiência técnica para as variáveis foi calculada igualando-se a zero a primeira derivada de cada equação de regressão.

\section{Resultados e Discussão}

A fonte de adubo nitrogenado não produzio efeito sobre as variáveis analisadas e nem interagiu significativamente com as demais fontes de variação (Tabela 2). Entretanto, as doses e os anos de experimentação apresentaram efeitos significativos

Tabela 1. Resultados das análises química e física do solo $(0,0-0,20 \mathrm{~m})$, antes da implantação dos experimentos.

\begin{tabular}{|c|c|c|c|c|c|c|c|c|c|c|c|c|}
\hline \multirow[t]{2}{*}{$\overline{\text { Ano }}$} & \multirow{2}{*}{$\begin{array}{c}\mathrm{pH} \\
\left(\mathrm{CaCl}_{2}\right)\end{array}$} & \multirow{2}{*}{$\begin{array}{c}\mathrm{MO}^{(1)} \\
\left(\mathrm{g} \mathrm{dm}^{-3}\right) \\
\end{array}$} & \multirow{2}{*}{\multicolumn{2}{|c|}{$\begin{array}{c}\mathrm{P} \\
---\left(\mathrm{mg} \mathrm{dm}^{-3}\right)^{----}\end{array}$}} & $\mathrm{H}+\mathrm{Al}$ & $\mathrm{Al}^{3+}$ & $\mathrm{Ca}^{2+}$ & $\mathrm{Mg}^{2+}$ & $\mathrm{K}^{+}$ & Areia & Silte & Argila \\
\hline & & & & & \multicolumn{5}{|c|}{ 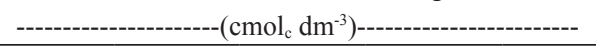 } & \multicolumn{3}{|c|}{----------( $\left(\mathrm{g} \mathrm{kg}^{-1}\right)----------$} \\
\hline 2009 & 5,0 & 48,90 & 15,6 & 12,4 & 6,21 & 0,00 & 6,34 & 2,47 & 0,26 & 110 & 140 & 750 \\
\hline 2010 & 4,7 & 36,90 & 13,0 & 13,3 & 7,20 & 0,00 & 5,04 & 2,30 & 0,18 & 90 & 130 & 780 \\
\hline
\end{tabular}

${ }^{(1)} \mathrm{MO}$, matéria orgânica do solo.

Tabela 2. Resumo da análise de variância.

\begin{tabular}{|c|c|c|c|c|c|c|c|c|c|c|}
\hline \multirow{2}{*}{$\begin{array}{l}\text { Fonte de } \\
\text { variação }\end{array}$} & \multirow[t]{2}{*}{ GL } & \multicolumn{9}{|c|}{ Quadrados médios } \\
\hline & & $\begin{array}{c}\text { Altura de planta } \\
(\mathrm{cm})\end{array}$ & NPM2 & $\begin{array}{c}\text { Área foliar } \\
\left(\mathrm{dm}^{2}\right)\end{array}$ & MSA & $\begin{array}{c}\text { MSP } \\
-(g) \\
\end{array}$ & MMG & $\begin{array}{c}\text { Produtividade } \\
\left(\mathrm{kg} \mathrm{ha}^{-1}\right)\end{array}$ & $\begin{array}{l}\text { Proteína } \\
---(\mathrm{g} \mathrm{kg}\end{array}$ & $\begin{array}{r}\text { Óleo } \\
\left.\mathrm{s}^{-1}\right)----- \\
\end{array}$ \\
\hline Bloco & 6 & 258,00 & 275,00 & 371,90 & 22,43 & 69,48 & 0,52 & 212.881 & 1,05 & 1,30 \\
\hline Ano (A) & 1 & $9.833,00 * *$ & $3.132,00 * *$ & $548,88^{\mathrm{ns}}$ & $1.198,32 * *$ & $6.682,00 * *$ & $0,76^{*}$ & $521.876^{* *}$ & $0,11^{\mathrm{ns}}$ & $2,19^{*}$ \\
\hline Fonte (B) & 1 & $36,29^{\mathrm{ns}}$ & $0,03^{\mathrm{ns}}$ & $91,66^{\mathrm{ns}}$ & $1,59^{\mathrm{ns}}$ & $0,73^{\mathrm{ns}}$ & $0,06^{\mathrm{ns}}$ & $50.773^{\mathrm{ns}}$ & $0,04^{\mathrm{ns}}$ & $0,00^{\mathrm{ns}}$ \\
\hline Dose $(C)$ & 6 & $628,00 * *$ & $66,93^{\mathrm{ns}}$ & $5.670,00^{* *}$ & $1.308,00 * *$ & $905,00 * *$ & $2,61 * *$ & $2.158 .172 * *$ & $89,22 * *$ & $48,51^{* *}$ \\
\hline $\mathrm{A} \times \mathrm{B}$ & 1 & $0,04^{\mathrm{ns}}$ & $0,00^{\mathrm{ns}}$ & $641,00^{\mathrm{ns}}$ & $3,21^{\mathrm{ns}}$ & $22,90^{\text {ns }}$ & $0,18^{\mathrm{ns}}$ & $36.683^{\mathrm{ns}}$ & $0,00^{\mathrm{ns}}$ & $0,09^{\text {ns }}$ \\
\hline $\mathrm{A} \times \mathrm{C}$ & 6 & $28,79 *$ & $2,68^{\mathrm{ns}}$ & $30,94^{\mathrm{ns}}$ & $40,53^{* *}$ & $182,00 * *$ & $0,21^{\mathrm{ns}}$ & $113.426^{*}$ & $0,25^{\text {ns }}$ & $0,36^{\mathrm{ns}}$ \\
\hline $\mathrm{B} \times \mathrm{C}$ & 6 & $9,56^{\mathrm{ns}}$ & $51,51^{\mathrm{ns}}$ & $193,16^{\mathrm{ns}}$ & $21,19^{\text {ns }}$ & $25,32^{\mathrm{ns}}$ & $0,10^{\mathrm{ns}}$ & $23.657^{\mathrm{ns}}$ & $0,47^{\mathrm{ns}}$ & $0,49^{\text {ns }}$ \\
\hline $\mathrm{A} \times \mathrm{B} \times \mathrm{C}$ & 6 & $9,38^{\mathrm{ns}}$ & $2,06^{\mathrm{ns}}$ & $166,41^{\mathrm{ns}}$ & $7,36^{\mathrm{ns}}$ & $42,91^{\text {ns }}$ & $0,11^{\mathrm{ns}}$ & $13.907^{\mathrm{ns}}$ & $0,41^{\mathrm{ns}}$ & $0,44^{\mathrm{ns}}$ \\
\hline Resíduo & 78 & 18,60 & 42,02 & 114,90 & 9,18 & 32,58 & 0,16 & 39.600 & 0,35 & 0,39 \\
\hline Média & - & 96,29 & 26,44 & 103,84 & 21,38 & 27,18 & 2,53 & 1.240 & 24,27 & 27,32 \\
\hline CV (\%) & - & 4,48 & 24,51 & 10,32 & 14,17 & 21,00 & 16,07 & 16,04 & 2,59 & 2,29 \\
\hline
\end{tabular}

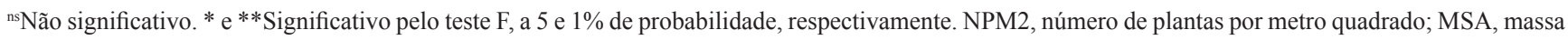
de matéria seca da parte aérea; MSP, massa de matéria seca de síliquas por planta; MMG, massa de mil grãos. 
sobre a maioria das variáveis avaliadas e interagiram significativamente entre si.

O experimento de 2009 apresentou maiores médias de massa de matéria seca da parte aérea (MSA) e de síliquas por planta (MSP), enquanto o experimento de 2010 apresentou maior altura de plantas e número de plantas por metro quadrado (NPM2) (Tabela 3). Estes resultados evidenciam a influência significativa dos fatores climáticos sobre as variáveis analisadas. Em maio de 2009, quando foi semeado o primeiro experimento (12/5/2009), registrou-se cerca de $400 \mathrm{~mm}$ de precipitação (Figura 1), o que provavelmente diminuiu o número de plântulas emergidas, com efeito direto sobre NPM2 e, consequentemente, sobre altura de plantas, MSA e MSP.

Em 2009, as doses de 20 e $40 \mathrm{~kg} \mathrm{ha}^{-1}$ de $\mathrm{N}$ proporcionaram massa de mil grãos (MMG) inferior à de 2010 (Tabela 3). Para a produtividade de grãos, além das doses de 20 e $40 \mathrm{~kg} \mathrm{ha}^{-1}$, as doses de 60 e $100 \mathrm{~kg} \mathrm{ha}^{-1}$ de $\mathrm{N}$ também proporcionaram desempenho inferior em 2009. Rathke et al. (2006) afirmam que a canola apresenta elevada plasticidade fenotípica para um grande número de variáveis, mas que esta plasticidade tem efeito limitado sobre a produtividade. Cheema et al. (2010) relataram que a produtividade de grãos da canola é determinada especialmente pelos componentes MSP e MMG. Portanto, em razão do efeito direto do NPM2 sobre esses componentes, a diminuição nos valores desta variável foi, possivelmente, a maior responsável pelas menores produtividades em 2009.

As doses de $\mathrm{N}$ produziram efeito significativo sobre altura de planta, MSA, área foliar (AF) e MSP (Figura 2), mas não influenciaram NPM2.

Quanto à altura de planta, a canola alcançou o maior desenvolvimento com as doses de 80 e $82 \mathrm{~kg} \mathrm{ha}^{-1}$ de $\mathrm{N}$, para 2009 e 2010, respectivamente (Figura 2). Essas doses resultaram em alturas de 91 e $116 \mathrm{~cm}$. Segundo Yasari et al. (2009), o N aumenta a taxa de conversão de carboidratos em proteínas e aumenta o tamanho da célula, o que é manifestado morfologicamente pela expansão da área foliar e por maiores taxas de crescimento.

Os maiores valores de MSA foram alcançados com 74 e $73 \mathrm{~kg} \mathrm{ha}^{-1}$ de $\mathrm{N}$, respectivamente, que resultaram em 29 e 28 g por planta (Figura 2). Cheema et al. (2010) constataram maior produção de MSA com $90 \mathrm{~kg} \mathrm{ha}^{-1}$ de N. Mandal \& Sinha (2004) observaram aumento na taxa de fotossíntese com $100 \mathrm{~kg} \mathrm{ha}^{-1}$ de N, além de concomitante incremento no aproveitamento da radiação solar, em razão do aumento de MAS pela adubação nitrogenada. Porém, diferentemente da resposta quadrática encontrada no presente trabalho, há relatos de respostas lineares da MSA de canola à adubação nitrogenada (El-Nakhlawy \& Barkhashwan, 2009; Sharifi et al., 2009).

Em relação à área foliar, houve melhor desempenho com 72 e $74 \mathrm{~kg} \mathrm{ha}^{-1}$ de $\mathrm{N}$, que proporcionaram 122 e $117 \mathrm{dm}^{2}$ de AF por planta, em 2009 e 2010, respectivamente (Figura 2). Rathke et al. (2006) verificaram aumento na área foliar com a aplicação de $75 \mathrm{~kg} \mathrm{ha}^{-1}$ de $\mathrm{N}$, além de incremento no número de flores por planta. De acordo com esses autores, o montante de radiação interceptada pela área foliar é afetado principalmente pela estrutura do dossel, em que a área foliar tem marcada influência e é diretamente influenciada pela adubação nitrogenada. Cheema et al. (2010) observaram incremento linear da área foliar de canola com o incremento na adubação nitrogenada. Portanto, parece desejável que se tenha plantas com grande área foliar, pois isso aumentaria a

Tabela 3. Média das variáveis biométricas e dos componentes de produção avaliados em canola, nos experimentos realizados em 2009 e $2010^{(1)}$.

\begin{tabular}{|c|c|c|c|c|c|c|c|c|c|c|c|c|c|c|c|c|c|c|}
\hline \multirow[t]{2}{*}{$\begin{array}{l}\text { Dose de N } \\
\left(\mathrm{kg} \mathrm{ha}^{-1}\right)\end{array}$} & \multicolumn{2}{|c|}{$\begin{array}{l}\text { Altura } \\
(\mathrm{cm})\end{array}$} & \multicolumn{2}{|c|}{ NPM2 } & \multicolumn{2}{|c|}{$\begin{array}{l}\text { MSA } \\
(\mathrm{g})\end{array}$} & \multicolumn{2}{|c|}{$\begin{array}{c}\text { Área foliar } \\
\left(\mathrm{dm}^{2}\right)\end{array}$} & \multicolumn{2}{|c|}{$\begin{array}{c}\mathrm{MSP} \\
(\mathrm{g})\end{array}$} & \multicolumn{2}{|c|}{$\begin{array}{c}\text { MMG } \\
(\mathrm{g})\end{array}$} & \multicolumn{2}{|c|}{$\begin{array}{c}\text { Produtividade } \\
\left(\mathrm{kg} \mathrm{ha}^{-1}\right)\end{array}$} & \multicolumn{2}{|c|}{$\begin{array}{c}\text { Proteína } \\
\left(\mathrm{g} \mathrm{kg}^{-1}\right)\end{array}$} & \multicolumn{2}{|c|}{$\begin{array}{c}\text { Óleo } \\
\left(\mathrm{g} \mathrm{kg}^{-1}\right)\end{array}$} \\
\hline & 2009 & 2010 & 2009 & 2010 & 2009 & 2010 & 2009 & 2010 & 2009 & 2010 & 2009 & 2010 & 2009 & 2010 & 2009 & 2010 & 2009 & 2010 \\
\hline 0 & $75,9 b$ & $89,6 \mathrm{a}$ & $22,2 b$ & $33,3 a$ & $11,0 \mathrm{a}$ & $8,0 \mathrm{~b}$ & $78,3 \mathrm{a}$ & $73,1 \mathrm{a}$ & $20,5 \mathrm{a}$ & $12,3 b$ & $1,8 \mathrm{a}$ & $1,8 \mathrm{a}$ & $628 \mathrm{a}$ & $689 a$ & $20,2 \mathrm{a}$ & $20,2 \mathrm{a}$ & $30,4 a$ & $29,7 \mathrm{a}$ \\
\hline 20 & $86,3 \mathrm{~b}$ & $105,4 a$ & $18,1 \mathrm{~b}$ & $27,2 \mathrm{a}$ & $17,6 \mathrm{a}$ & $12,5 b$ & $93,3 \mathrm{a}$ & $89,9 \mathrm{a}$ & $24,9 \mathrm{a}$ & $16,4 \mathrm{~b}$ & $2,1 b$ & $2,6 \mathrm{a}$ & $830 \mathrm{~b}$ & $1.057 \mathrm{a}$ & $22,7 \mathrm{a}$ & $21,9 \mathrm{a}$ & $28,8 \mathrm{a}$ & $28,8 \mathrm{a}$ \\
\hline 40 & $87,7 \mathrm{~b}$ & $106,1 \mathrm{a}$ & $22,0 \mathrm{~b}$ & $33,0 \mathrm{a}$ & $22,1 \mathrm{a}$ & $15,6 b$ & $105,0 \mathrm{a}$ & $97,8 \mathrm{a}$ & $30,4 a$ & $17,3 b$ & $2,3 b$ & $2,7 \mathrm{a}$ & $1.018 \mathrm{~b}$ & $1.250 \mathrm{a}$ & $24,0 \mathrm{a}$ & $24,2 \mathrm{a}$ & $27,9 \mathrm{a}$ & $27,9 \mathrm{a}$ \\
\hline 60 & $88,9 b$ & $110,1 \mathrm{a}$ & $22,2 b$ & $33,4 \mathrm{a}$ & $30,4 \mathrm{a}$ & $23,2 b$ & $118,1 \mathrm{a}$ & $114,3 \mathrm{a}$ & $39,3 \mathrm{a}$ & $20,3 b$ & $2,7 \mathrm{a}$ & $2,8 \mathrm{a}$ & $1.234 \mathrm{~b}$ & $1.450 \mathrm{a}$ & $24,9 \mathrm{a}$ & $25,2 \mathrm{a}$ & $27,4 \mathrm{a}$ & $27,1 \mathrm{a}$ \\
\hline 80 & $91,0 \mathrm{~b}$ & $108,1 \mathrm{a}$ & $22,8 b$ & $34,2 \mathrm{a}$ & $44,0 \mathrm{a}$ & $31,0 \mathrm{~b}$ & $139,0 \mathrm{a}$ & $130,5 \mathrm{a}$ & $51,3 \mathrm{a}$ & $24,6 b$ & $3,1 \mathrm{a}$ & $2,9 a$ & $1.764 \mathrm{a}$ & $1.563 b$ & $25,8 \mathrm{a}$ & $25,6 \mathrm{a}$ & $26,7 \mathrm{a}$ & $26,3 \mathrm{a}$ \\
\hline 100 & $90,9 b$ & $112,4 a$ & $20,5 b$ & $30,7 \mathrm{a}$ & $26,6 \mathrm{a}$ & $26,7 \mathrm{a}$ & $109,5 \mathrm{a}$ & $109,3 \mathrm{a}$ & $44,1 \mathrm{a}$ & $24,1 \mathrm{~b}$ & $2,7 \mathrm{a}$ & $2,9 a$ & $1.515 \mathrm{~b}$ & $1.815 \mathrm{a}$ & $26,4 \mathrm{a}$ & $26,2 \mathrm{a}$ & $25,9 \mathrm{a}$ & $25,3 \mathrm{a}$ \\
\hline 120 & $87,8 \mathrm{~b}$ & $107,9 \mathrm{a}$ & $20,2 \mathrm{~b}$ & $30,3 \mathrm{a}$ & $20,8 \mathrm{a}$ & $15,9 \mathrm{~b}$ & $99,2 \mathrm{a}$ & $96,4 \mathrm{a}$ & $33,9 \mathrm{a}$ & $21,3 \mathrm{~b}$ & $2,4 \mathrm{a}$ & $2,4 \mathrm{a}$ & $1.218 \mathrm{a}$ & $1.341 \mathrm{a}$ & $27,1 \mathrm{a}$ & $26,8 \mathrm{a}$ & $25,1 \mathrm{a}$ & $25,2 \mathrm{a}$ \\
\hline
\end{tabular}

${ }^{(1)}$ Médias seguidas da letras iguais, na linha, não diferem pelo teste $t$ de Student, a $5 \%$ de probabilidade. NPM2, número de plantas por metro quadrado; MSA, massa de matéria seca da parte aérea; MSP, massa de matéria seca de síliquas por planta; MMG, massa de mil grãos. 
interceptação da energia solar. Além disso, espera-se o aumento da eficiência fotossintética das plantas pela suplementação adequada de N (Marenco \& Lopes, 2005; Rathke et al., 2006).

As doses de 83 e $98 \mathrm{~kg} \mathrm{ha}^{-1}$ de $\mathrm{N}$ proporcionaram 43 e 23 g de síliquas por planta, em 2009 e 2010, respectivamente (Figura 2). À semelhança da área foliar, foi observada maior eficiência da adubação nitrogenada em 2009. Ao avaliar a influência de doses de N sobre MSP, Ahmadi \& Bahrani (2009) e Sharifi et al. (2009), no Irã, bem como El-Nakhlawy \& Bakhashwain (2009), no Egito, obtiveram maior número de síliquas por planta com 225, 150 e $184 \mathrm{~kg} \mathrm{ha}^{-1}$ de $\mathrm{N}$, respectivamente, que proporcionaram 152,85 e 206 síliquas por planta e produtividades de $3.251,1.167$ e $1.489 \mathrm{~kg} \mathrm{ha}^{-1}$. No presente trabalho,
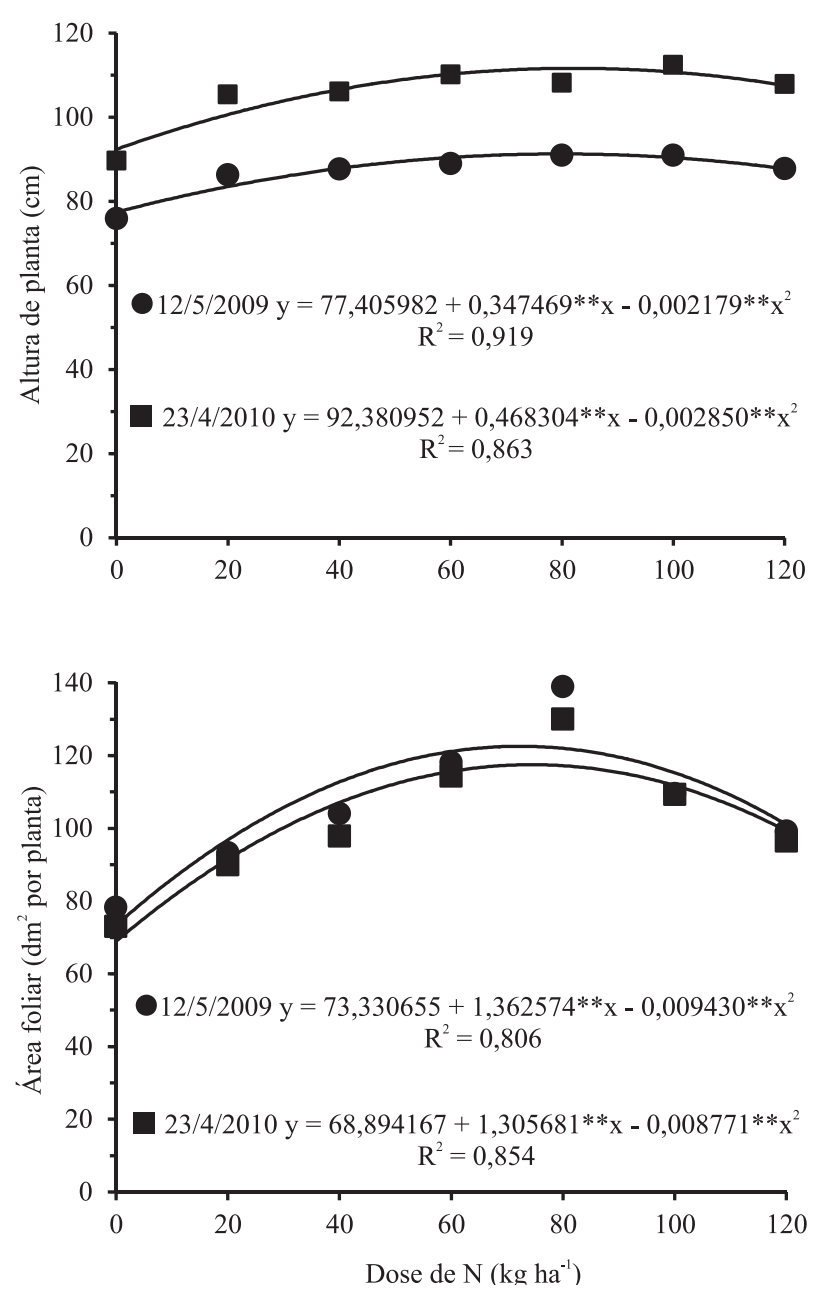

a dose de $83 \mathrm{~kg} \mathrm{ha}^{-1}$ de $\mathrm{N}$, em 2009, proporcionou a maior MSP e produtividade de $1.468 \mathrm{~kg} \mathrm{ha}^{-1}$. Essa dose é relativamente baixa se comparada às utilizadas nos demais estudos.

No Brasil, a canola não parece tão responsiva à aplicação de $\mathrm{N}$ quanto em outros países, possivelmente em razão das altas temperaturas que ocorrem comumente durante o estádio reprodutivo da cultura. Ortegón Morales et al. (2006) e Tomm et al. (2009) concluíram que temperaturas acima de $27^{\circ} \mathrm{C}$ durante o florescimento impactam negativamente o rendimento de grãos, pois aumentam o abortamento de flores e de síliquas em início de formação.

Quanto à MMG, as maiores médias foram obtidas com 79 e $72 \mathrm{~kg} \mathrm{ha}^{-1}$ de $\mathrm{N}$, que proporcionaram, respectivamente, 2,8 e $3 \mathrm{~g}$ em 2009 e 2010 (Figura 3).
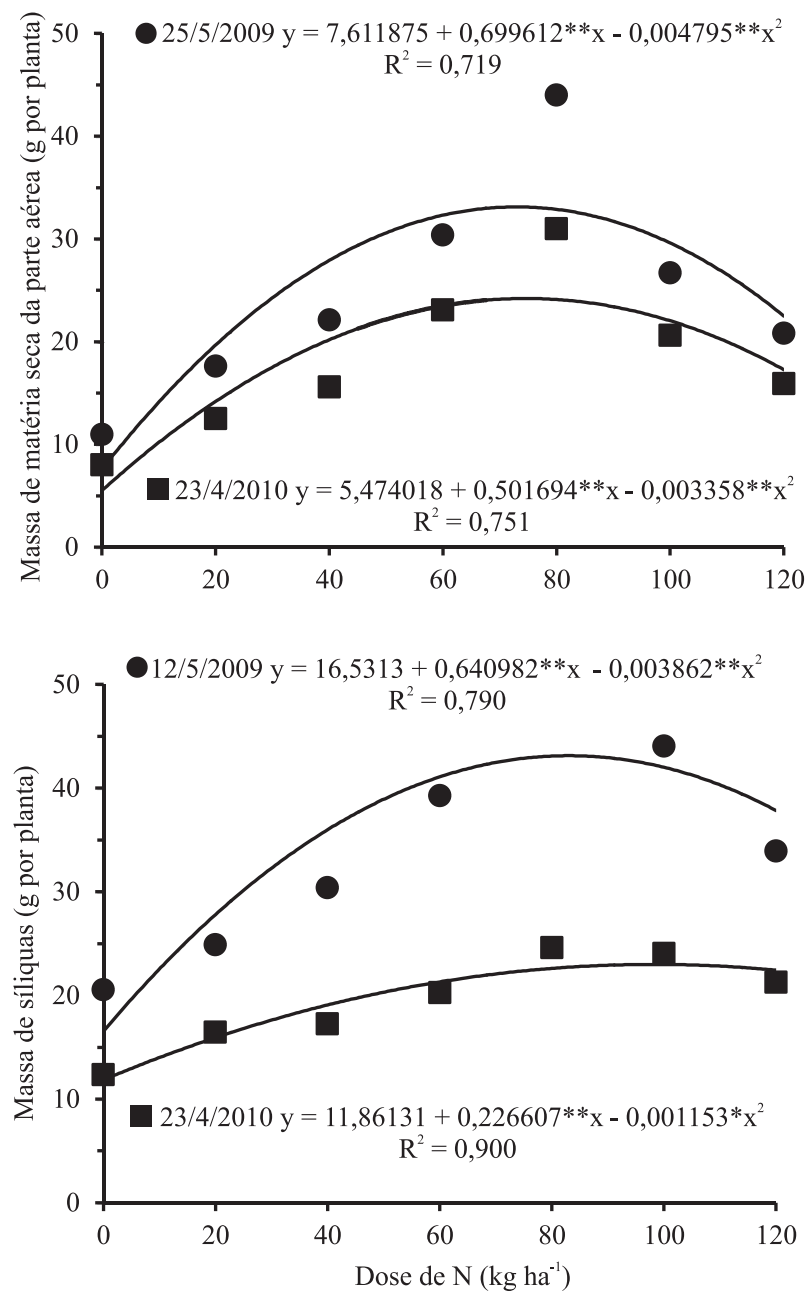

Figura 2. Altura de planta, massa de matéria seca da parte aérea, área foliar e massa de síliquas por planta, em canola, híbrido Hyola 61, de acordo com as doses de $\mathrm{N}$ aplicadas em dois experimentos, semeados em 12/5/2009 e 23/4/2010. **Significativo pelo teste t de Student, a $1 \%$ de probabilidade. 
Mesmo o resultado de 3 g, obtido com a dose de $72 \mathrm{~kg} \mathrm{ha}^{-1}$ de $\mathrm{N}$, é relativamente inferior ao citado na literatura internacional. Na Turquia, Öztürk (2010) obteve MMG de 4,3 g com o fornecimento de $150 \mathrm{~kg} \mathrm{ha}^{-1}$ de N. No Egito, El-Habbasha \& El-Salam (2010) constataram resposta linear da MMG à aplicação de $\mathrm{N}$, em que a dose de $143 \mathrm{~kg} \mathrm{ha}^{-1}$ de $\mathrm{N}$ proporcionou $\mathrm{MMG}$ de 3,57 g. No Paquistão, Karaaslan (2008) obteve MMG de 4,0 g, com a aplicação de $90 \mathrm{~kg} \mathrm{ha}^{-1}$ de N. Dessa forma, a resposta desse caráter à adubação nitrogenada foi maior nesses países do que no presente trabalho, provavelmente por essas regiões apresentarem condições climáticas mais adequadas ao cultivo da canola, especialmente temperaturas mais amenas. Não foram encontradas referências de trabalhos sobre a MMG realizados no Brasil.
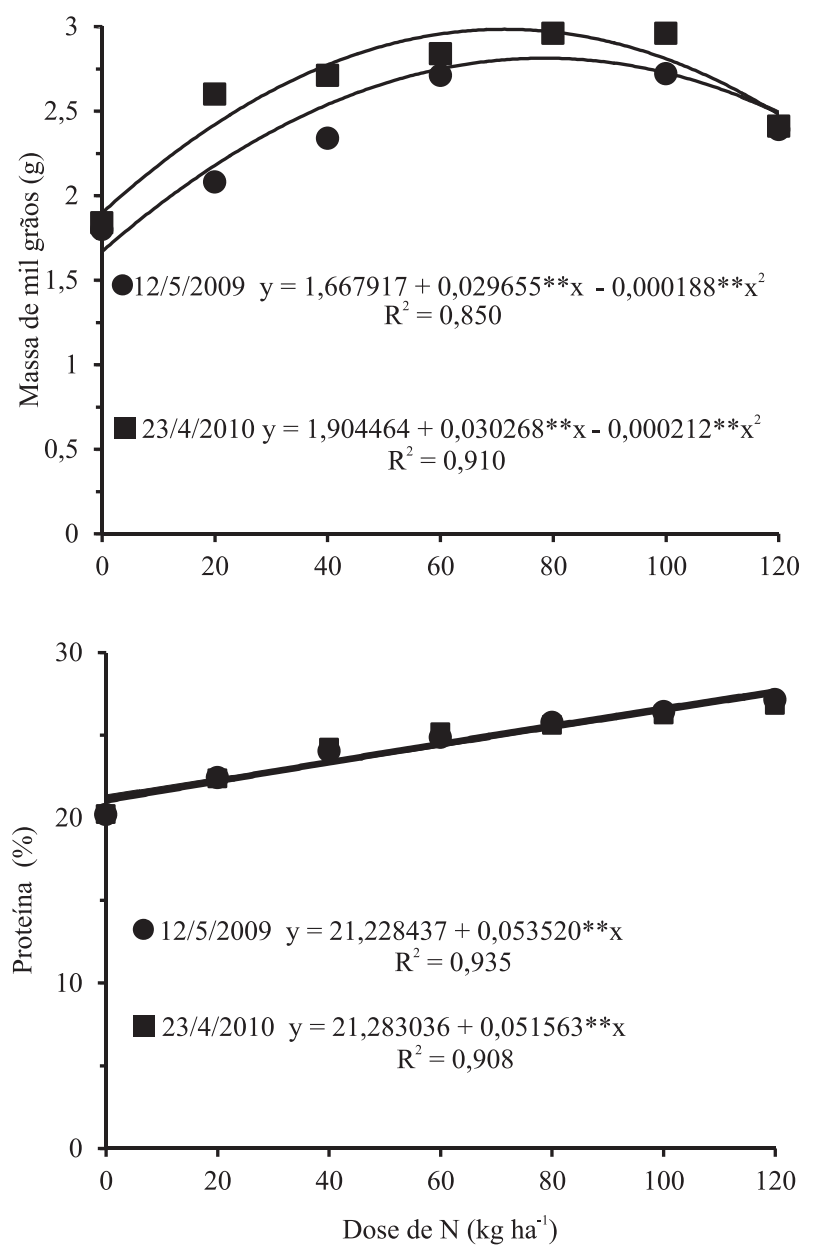

Os melhores resultados de produtividade foram obtidos com 89 e $88 \mathrm{~kg} \mathrm{ha}^{-1}$ de N, em 2009 e 2010 , respectivamente, que proporcionaram $1.465 \mathrm{e}$ $1.598 \mathrm{~kg} \mathrm{ha}^{-1}$ de grãos (Figura 3). Portanto, no caso da produtividade, a adubação nitrogenada em 2010 foi a que apresentou maior eficiência, com maior produtividade em dose menor que em 2009. Mais uma vez, o maior NPM2 em 2010 deve ter sido responsável pela diferença nos resultados. De acordo com Rathke et al. (2006), a densidade de plantas é a variável que mais influencia os componentes de produção e a produtividade.

Em 2009, também é possível que a época de semeadura tardia tenha influenciado negativamente a produtividade. Para híbridos de ciclo precoce em solos argilosos, a época recomendada para semeadura vai de 1 de março a 31 de maio (Brasil,
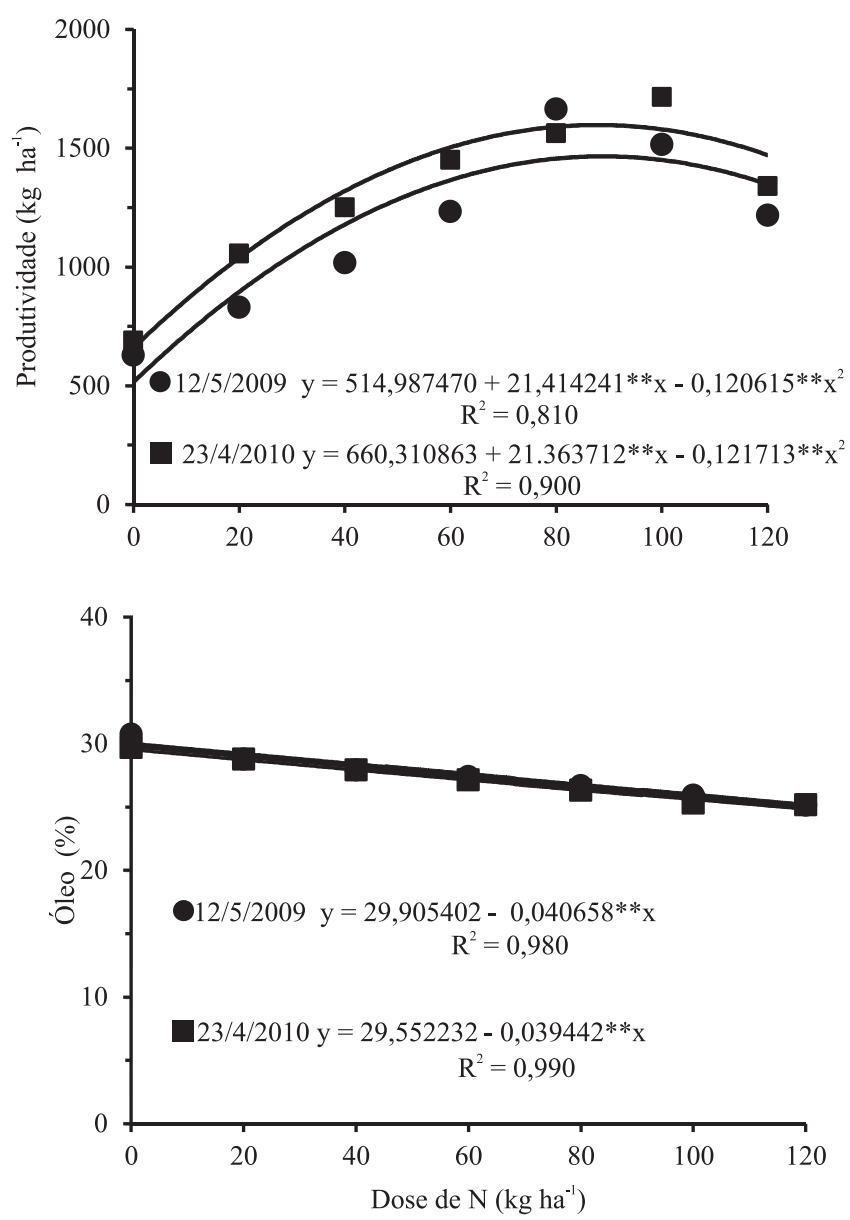

Figura 3. Massa de mil grãos, produtividade de grãos, e teor de proteína e de óleo nos grãos de canola, híbrido Hyola 61, de acordo com as doses de $\mathrm{N}$ aplicadas em dois experimentos, semeados em 12/5/2009 e 23/4/2010. **Significativo pelo teste t de Student, a $1 \%$ de probabilidade. 
2011), mas as semeaduras precoces são favorecidas em termos de produtividade (Edwards \& Martin, 2009). A produtividade de $1.598 \mathrm{~kg} \mathrm{ha}^{-1}$, alcançada com a dose de $88 \mathrm{~kg} \mathrm{ha}^{-1}$ de $\mathrm{N}$, é condizente com as comumente alcançadas no Brasil. Tomm et al. (2009), por exemplo, verificaram que a aplicação de $60 \mathrm{~kg} \mathrm{ha}^{-1}$ de $\mathrm{N}$ elevou a produtividade de 717 para $1.517 \mathrm{~kg} \mathrm{ha}^{-1}$. No entanto, em termos mundiais, as respostas produtivas da cultura a doses de $\mathrm{N}$ são bem mais elevadas. Em trabalho conduzido na Estônia, Narits (2010) obteve produtividade de $5.356 \mathrm{~kg} \mathrm{ha}^{-1}$, com a aplicação de $120 \mathrm{~kg} \mathrm{ha}^{-1}$ de $\mathrm{N}$. Cheema et al. (2010), no Paquistão, obtiveram $2.812 \mathrm{~kg} \mathrm{ha}^{-1}$ de grãos, também com $120 \mathrm{~kg} \mathrm{ha}^{-1}$ de N. No Canadá, Karamanos et al. (2006) obtiveram $2.600 \mathrm{~kg} \mathrm{ha}^{-1}$ de grãos com a aplicação de $160 \mathrm{~kg} \mathrm{ha}^{-1}$ de N. Rathke et al. (2006), na Alemanha, obtiveram $4.900 \mathrm{~kg} \mathrm{ha}^{-1}$ de grãos com $240 \mathrm{~kg} \mathrm{ha}^{-1}$ de $\mathrm{N}$. Vale salientar que a canola semeada no Brasil é de primavera, com ciclo mais curto e com menor potencial de produção que a semeada na Europa, nos EUA e no Canadá, que é a canola de inverno, com ciclo mais longo e alto potencial produtivo.

Desse modo, as doses de $\mathrm{N}$ que proporcionam as melhores respostas para as variáveis biométricas MSA e área foliar, bem como para os componentes de produção MSP e MMG, foram as que proporcionaram os melhores resultados produtivos. Assim, de maneira geral, a aplicação de $88 \mathrm{~kg} \mathrm{ha}^{-1}$ de $\mathrm{N}$ na semeadura foi a dose com os melhores resultados.

Quanto aos teores de proteína nos grãos, houve resposta linear à aplicação de $\mathrm{N}$, em que a dose máxima de $120 \mathrm{~kg}^{-1}$ de $\mathrm{N}$ proporcionou média de $27 \%$ de proteína (Figura 3). Esses resultados são condizentes com os relatados por Tomm et al. (2009), no Brasil. Entretanto, em outros países, os teores de proteínas observados têm sido relativamente menores. Na Turquia, Öztürk (2010) reportou 23,9\% de proteína com a dose de $150 \mathrm{~kg} \mathrm{ha}^{-1}$ de N. Na Alemanha, Rathke et al. (2006) obtiveram o maior teor de proteína $(22,5 \%)$ com $240 \mathrm{~kg} \mathrm{ha}^{-1}$ de N. No Paquistão, Karaaslan (2008) obteve $21,45 \%$ de proteína com a aplicação de $120 \mathrm{~kg} \mathrm{ha}^{-1}$ de N.

Já os teores de óleo nos grãos apresentaram resposta linear negativa à adubação nitrogenada, com os maiores teores observados na testemunha, com média entre os dois experimentos de $30 \%$ de óleo (Figura 3). Esses teores estão abaixo da média brasileira e da mundial. No Brasil, os teores variam de 38\% (Tomm et al., 2009) a 45\% (Cordeiro et al., 1999). No Paquistão,
Cheema et al. (2010) encontraram teores de 46,3\% sem a adubação nitrogenada e de $42,5 \%$ com a aplicação de $120 \mathrm{~kg} \mathrm{ha}^{-1}$ de N.

Os menores teores de óleo obtidos no presente trabalho podem ter sido influenciados pelas altas temperaturas observadas durante o enchimento de grãos (Figura 1). De acordo com Walton et al. (2000), altas temperaturas durante o enchimento de grãos, estresse hídrico e altas doses de $\mathrm{N}$ diminuem a concentração de óleo na massa de grãos de canola. Esses autores relataram que a maior produção de óleo pela canola ocorre nas faixas de temperatura de 13 a $22^{\circ} \mathrm{C}$, e que a fase de enchimento de grãos é especialmente sensível a altas temperaturas. Tomm et al. (2009) constataram redução de $1,5 \%$ nos teores de óleo para cada grau centígrado de incremento na temperatura, durante o período de enchimento de grãos. Para Gunasekera et al. (2006), a temperatura é o fator ambiental mais importante entre os que regulam a concentração de óleo nos grãos de canola. Segundo Rathke et al. (2006), os teores de óleo e proteína correlacionam-se negativamente e reagem de forma oposta à temperatura: temperaturas mais altas durante a maturação reduzem o conteúdo de óleo e aumentam o de proteína.

\section{Conclusões}

1. O desempenho agronômico da canola não é influenciado pelas fontes de $\mathrm{N}$ utilizadas, sulfato de amônio e ureia.

2. A dose de $88 \mathrm{~kg} \mathrm{ha}^{-1}$ de $\mathrm{N}$ proporciona os melhores resultados produtivos em canola.

3. O conteúdo de proteína nos grãos de canola aumenta com a adubação nitrogenada, enquanto o de óleo diminui.

\section{Referências}

AHMADI, M.; BAHRANI, M.J. Yield and yield components of rapeseed as influenced by water stress at different growth stages and nitrogen levels. American-Eurasian Journal of Agriculture Environmental Science, v.5, p.755-761, 2009.

BENINCASA, M.M.P. Análise de crescimento de plantas: noções básicas. Jaboticabal: Funep, 1988. 42p.

BRASIL. Ministério da Agricultura, Pecuária e Abastecimento. Portaria $n^{\circ} 481$ de 13 de dezembro de 2011. Aprova o zoneamento agrícola de risco climático para a cultura de canola no Estado do Paraná, ano-safra 2011/2012. Diário Oficial [da] República Federativa do Brasil, 15 dez. 2012. Seção 1.

CHEEMA, M.A.; SALEEM, M.F.; MUHAMMAD, N.; WAHID, M.A.; BABER, B.H. Impact of rate and timing of nitrogen 
application on yield and quality of canola (Brassica napus L.). Pakistan Journal of Botany, v.42, p.1723-1731, 2010.

CORDEIRO, L.A.M.; REIS, M.S.; ALVARENGA, E.M. A cultura da canola. Viçosa: Ed. da UFV, 1999. 50p.

EDWARDS, J.; MARTIN, P. The effect of sowing time on the yield and quality of canola (Brassica napus) - preliminary findings. 2009. Available at: <http://www.australianoilseeds. com/_data/assets/pdf_file/0007/6892/Effect_of_sowing_time on the yield quality_of canola_Brassica napus.pdf $>$. Accessed on: 11 July 2011.

EL-HABBASHA, S.F.; EL-SALAM, M.S. Response of two canola varieties (Brassica napus L.) to nitrogen fertilizer levels and zinc foliar application. International Journal of Academic Research, v.2, p.60, 2010.

EL-NAKHLAWY, F.S.; BAKHASHWAIN, A.A. Performance of canola (Brassica napas L.) seed yield, yield components and seed quality under the effects of four genotypes and nitrogen fertilizer rates. Meteorology, Environmental and Arid Land Agriculture Science, v.20, p.33-47, 2009.

FERREIRA, D.F. Manual do sistema Sisvar para análises estatísticas. Lavras: Ed. da UFLA, 2009. 66p.

GUNASEKERA, C.P.; MARTIN, L.D.; SIDDIQUE, K.H.M.; WALTON, G.H. Genotype by environment interactions of Indian mustard (Brassica juncea L.) and canola (Brassica napus L.) in Mediterranean-type environments II. Oil and protein concentrations in seed. European Journal of Agronomy, v.25, p.13-21, 2006. DOI: $10.1016 /$ j.eja.2005.08.002.

JONES, D.B. Factors for converting percentages of nitrogen in foods and feeds into percentages of protein. Washington: United State Department of Agriculture, 1931. 21p. (USDA. Circular, 183).

KARAASLAN, D. The effect of different nitrogen doses on seed yield, oil, protein and nutrient contents of spring rape. Pakistan Journal of Botany, v.40, p.807-813, 2008.

KARAMANOS, R.E.; GOH, T.B.; FLATEN, D.N. Nitrogen and sulphur fertilizer management for growing canola on sulphur sufficient soils. Canadian Journal of Plant Science, v.87, p.201-210, 2006. DOI: 10.4141/P06-133.

MANDAL, K.G.; SINHA, A.C. Nutrient management effects on light interception, photosynthesis, growth, dry-matter production and yield of Indian mustard (Brassica juncea). Journal of Agronomy and Crop Science, v.190, p.119-129, 2004. DOI: 10.1046/j.1439-037X.2003.00083.x.

MARENCO, R.A.; LOPES, N.F. Fisiologia vegetal: fotossíntese, respiração, relações hídricas e nutrição mineral. Viçosa: Ed. da UFV, 2005. 439p.

MIYAZAWA, M.; PAVAN, M.A.; BLOCH, M. de F.M. Análise química de tecido vegetal. Londrina: Iapar, 1992. 17p. (Iapar. Circular, 74).
NARITS, L. Effect of nitrogen rate and application time to yield and quality of winter oilseed rape (Brassica napus L. var. oleifera subvar. biennis). Agronomy Research, v.8, p.671-686, 2010.

ORTEGÓN MORALES, A.S.; FRANCO, A.D.; QUINTERO, J.G.; CANO, I.G. La temperatura en la etapa reproductiva del cultivo de canola (Brassica napus L.). Agricultura Técnica en México, v.32, p.259-265, 2006.

ÖZTÜRK, Ö. Effects of source and rate of nitrogen fertilizer on yield, yield components and quality of winter rapeseed (Brassica napus L.). Chilean Journal of Agricultural Research, v.70, p.132-141, 2010. DOI: 10.4067/S0718-58392010000100014.

RATHKE, G.-W.; BEHRENS, B.; DIEPENBROCK, W. Integrated nitrogen management strategies to improve seed yield, oil content and nitrogen efficiency of winter oilseed rape (Brassica napus L.): a review. Agriculture, Ecosystems and Environment, v.117, p.80-108, 2006. DOI: 10.1016/j.agee.2006.04.006.

REGRAS para análise de sementes. Brasília: Ministério da Agricultura, Pecuária e Abastecimento, 2009. 395p.

SANTOS, H.G. dos; JACOMINE, P.K.T.; ANJOS, L.H.C. dos; OLIVEIRA, V.A. de; OLIVEIRA, J.B. de; COELHO, M.R.; LUMBRERAS, J.F.; CUNHA, T.J.F. (Ed.). Sistema brasileiro de classificação de solos. 2.ed. Rio de Janeiro: Embrapa Solos, 2006. $306 \mathrm{p}$.

SIMEPAR. Simepar. Disponível em: <http://www.simepar.br/>. Acesso em: 18 fev. 2014.

SHARIFI, R.S.; ZADEH, M.Z.; SEIEDI, M.N. Evaluation of yield and growth indices of canola (Brassica napus L.) cultivars in different nitrogen fertilization levels. Journal of Phytology, v.1, p.475-481, 2009

SILVA, D.J. da. Análise de alimentos: métodos químicos e biológicos. 2.ed. Viçosa: Ed. da UFV, 1990. 165p.

TEDESCO, M.J.; GIANELLO, C.; BISSANI, C.A.; BOHNEN, H.; VOLKWEISS, S.J. Análise de solo, plantas e outros materiais. 2.ed. rev. ampl. Porto Alegre: Ed. da UFRGS, 1995. 174p. (UFRGS. Boletim técnico, 5).

TOMM, G.O.; WIETHÖLTER, S.; DALMAGO, G.A.; SANTOS, H.P. dos. Tecnologia para produção de canola no Rio Grande do Sul. Passo Fundo: Embrapa Trigo, 2009. 41p. (Embrapa Trigo. Documentos, 92).

WALTON, G.; MENDHAM, N.; ROBERTSON, M.; POTTER, T. Phenology, physiology and agronomy. 2000. Available at: $<\mathrm{http}: / /$ regional.org.au/au/gcirc/canola/p-04.htm?print=1>. Accessed on: 17 July 2011.

YASARI, M.A.E.; AZADGOLEH, E.; MOZAFARI, S.; ALASHTI, M.R. Enhancement of growth and nutrient uptake of rapeseed (Brassica napus L.) by applying mineral nutrients and biofertilizers. Pakistan Journal of Biological Sciences, v.12, p.127-133, 2009. DOI: 10.3923/pjbs.2009.127.133.

Recebido em 18 de fevereiro de 2014 e aprovado em 13 de abril de 2014

Pesq. agropec. bras., Brasília, v.49, n.4, p.273-280, abr. 2014

DOI: 10.1590/S0100-204X2014000400005 